\title{
EFEITO DO CONDICIONAMENTO OSMÓTICO DAS SEMENTES NA GERMINAÇÃO E NO CRESCIMENTO DAS PLÂNTULAS DE ASPARGO ${ }^{1}$
}

\author{
MÁRIO LÚCIO CARVALHO BITTENCOURT ${ }^{2}$; DENISE CUNHA FERNANDES DOS SANTOS DIAS ${ }^{3}$; \\ LUIZ ANTÔNIO DOS SANTOS DIAS ${ }^{4}$; EDUARDO FONTES ARAÚJO ${ }^{3}$
}

\begin{abstract}
RESUMO - O tempo para germinação e emergência das plântulas de aspargo é relativamente longo, podendo levar de quatro a seis semanas, justificando o uso de técnicas que acelerem a germinação, como o condicionamento osmótico das sementes. Este trabalho teve por objetivo avaliar o efeito de diferentes tratamentos de condicionamento osmótico na germinação e no crescimento das plântulas de aspargo. Sementes de quatro lotes de aspargo 'Mary Washington' foram condicionadas em soluções de polietileno glicol (PEG 6000) a -1,0 e -1,2 MPa por sete e 14 dias, em água do mar a -3,3 MPa por sete e 14 dias e em água destilada por três dias. Sementes não condicionadas foram utilizadas como testemunha. O efeito dos tratamentos na qualidade fisiológica das sementes foi avaliado pelos testes de germinação e primeira contagem da germinação, velocidade de emergência das plântulas e comprimento da radícula, da plântula e do epicótilo. $\mathrm{O}$ experimento foi instalado no delineamento inteiramente casualizado, com quatro repetições e oito tratamentos. O condicionamento em PEG foi o tratamento mais adequado para promover a melhoria no desempenho das sementes. O condicionamento osmótico permitiu aumentar a germinação apenas das sementes de menor qualidade fisiológica. Efeitos benéficos do condicionamento osmótico foram mais expressivos na velocidade de emergência e no crescimento das plântulas, independentemente do nível de qualidade fisiológica das sementes.
\end{abstract}

Termos para indexação:Aspargus officinalis, condicionamento fisiológico, qualidade fisiológica.

\section{EFFECT OF SEED PRIMING ON GERMINATION AND SEEDLING GROWTH OF ASPARAGUS (Asparagus officinalis L.)}

\begin{abstract}
The time for germination and seedling emergence of asparagus is relatively long, taking four to six weeks, justifying the use of techniques that increase the germination rate as seed priming. The objective of this work was to evaluate the effect of asparagus seed priming on germination and seedling growth. Four seed lots of asparagus 'Mary Washington' were primed in polyethylene glycol (PEG 6000) solutions at $-1,0$ and $-1,2$ $\mathrm{MPa}$ during seven and 14 days, in seawater at -3,3 MPa during seven and 14 days, and distilled water for three days at $25^{\circ} \mathrm{C}$. Unprimed seeds were used as control. The effect of the treatments in the seed physiological quality was evaluated by germination (first count and final count), emergence rate, and radicle, epicotyl and seedling length. The experiment was arranged in a completely randomized design, with four replications and eight treatments. The osmotic conditioning in PEG was the most suitable treatment to improve the performance of asparagus seeds. Priming increased germination in seeds with low physiological quality only. The major effect of priming was on seedling emergence rate and growth, independently of seed physiological quality.
\end{abstract}

Index terms: Asparagus officinalis, osmotic conditioning, physiological quality.

\footnotetext{
${ }^{1}$ Submetido em 22/07/2003, Aceito para publicação em 29/01/2004. Parte da Tese de Doutorado do primeiro autor, apresentada à Universidade Federal de Viçosa (UFV).

${ }^{2} \mathrm{Eng}^{\mathrm{O}} \mathrm{Agr}^{\mathrm{o}}$, Dr., Prof. do Depto. de Fitotecnia - Escola Superior de Agricultura e Ciências de Machado (ESACMA), 37.750-000
}

\footnotetext{
Machado - MG; e-mail: mlucio.esacma@ fem.com.br

${ }^{3} \mathrm{Eng}^{\mathrm{o}} \mathrm{Agr}^{\mathrm{o}}$, Dr., Prof. Adjunto do Depto. de Fitotecnia - UFV, 36.571000 Viçosa - MG.

${ }^{4} \mathrm{Eng}^{\mathrm{o}} \mathrm{Agr}^{\mathrm{o}}$, Dr., Pesquisador do Depto. de Biologia Geral / BIOAGRO - UFV, 36.571-000 Viçosa - MG.
} 


\section{INTRODUÇÃO}

As sementes de aspargo apresentam germinação e emergência lentas, podendo ser o tempo decorrido da semeadura até o estabelecimento das plântulas de quatro a seis semanas, dependendo da temperatura e da umidade do solo. Isto poderá ter reflexo no ciclo de produção da cultura, e justificam o uso de técnicas que acelerem a germinação, como o condicionamento osmótico.

Esta técnica da hidratação controlada das sementes pode ser obtida pela embebição direta em água ou em soluções osmóticas. Estas soluções apresentam um potencial osmótico suficientemente adequado para evitar a protrusão da raiz primária, mas capaz de promover a embebição, de modo a estimular as atividades metabólicas que ocorrem nas fases preparatórias do processo de germinação (Bradford, 1986 e Khan, 1992). Dessa forma, durante o osmocondicionamento ocorre o desdobramento das substâncias de reserva e a síntese de compostos necessários ao processo germinativo, resultando em germinação mais rápida mesmo sob condições de estresses (Khan et al., 1978). A técnica de condicionamento osmótico acelera a germinação, permitindo a emergência mais rápida e uniforme das plântulas no campo. Além disso, tem sido relatado que o condicionamento pode melhorar o desenvolvimento das plântulas, conforme estudos conduzidos com alface (Wurr \& Fellows, 1984), salsa (Pill, 1986), tomate (Odell \& Cantliffe, 1986), pimentão (Stoffella et al., 1992) e brócoli (Jett \& Welbaum, 1996).

Dentre os principais fatores que determinam o sucesso do condicionamento osmótico têm-se o período de exposição das sementes a um agente osmótico (Pill \& Finch-Savage, 1988 e Evans \& Pill, 1989), a temperatura de condicionamento, o potencial osmótico (Haigh \& Barlow, 1987; Evans \& Pill, 1989), bem como a natureza do agente osmótico (Bradford, 1986; Haigh \& Barlow, 1987).

O agente osmótico mais comumente utilizado é o polietileno glicol - PEG (Pill \& Finch-Savage, 1988; Pill et al., 1991), por não ser fitotóxico, não atravessar o sistema de membranas e não ser metabolizado pelas sementes. Sais inorgânicos como $\mathrm{MnSO}_{4}, \mathrm{MgCl}_{2}, \mathrm{NaCl}$ e $\mathrm{NaNO}_{3}$ (Haigh \& Barlow, 1987), bem como água do mar sintética (Frett et al., 1991), também são utilizados como agentes condicionadores. No entanto, íons dissociados desses sais podem penetrar nos tecidos das sementes afetando o seu metabolismo (Frett et al., 1991).

Efeitos positivos do condicionamento osmótico têm sido relatados principalmente para sementes de hortaliças. Contudo, a obtenção de resultados satisfatórios depende, dentre outros fatores, da definição de um ajuste osmótico adequado e da qualidade inicial do lote de sementes. Parera \& Cantliffe (1994) sugerem o uso de sementes de alto vigor como pré-requisito para se obter um bom resultado. No entanto, de acordo com Szafirowska et al. (1981), o condicionamento osmótico tem se mostrado mais eficiente para revigorar sementes de cenoura de baixa qualidade fisiológica. Assim, outro fator que influencia o sucesso do condicionamento osmótico é a qualidade inicial do lote de sementes (Nascimento, 1998). A maioria dos trabalhos com sementes de aspargo avalia os efeitos do condicionamento aplicado a um único lote de sementes (Kharup, 1988; Evans \& Pill, 1989; Frett et al., 1991). Torna-se interessante, portanto, testar a eficiência desta técnica em lotes com níveis distintos de qualidade inicial.

Em sementes de aspargo, Evans \& Pill (1989) verificaram que, independente das condições de condicionamento (potencial osmótico, temperatura e duração do processo), as sementes condicionadas germinaram mais rapidamente do que as não condicionadas, embora o tratamento não tenha afetado a porcentagem final de germinação. Resultados semelhantes já haviam sido observados por Kharup (1988) ao condicionarem as sementes de aspargo em $\mathrm{MgSO}_{4}$ e em PEG 8000. Redução no tempo necessário para a germinação também foi constatada por Frett et al. (1991) em sementes de aspargo condicionadas em PEG 8000, em água do mar sintética e em soluções salinas. Por sua vez, Tiessen et al. (1983) concluíram que o uso de $\mathrm{KNO}_{3}$ ou PEG 8000 como agentes condicionadores não teve efeito sobre o vigor das sementes de aspargo. Contudo, é importante considerar que estes autores avaliaram os efeitos do condicionamento osmótico em um único lote de sementes, sendo escassas as informações sobre os benefícios desta técnica em lotes com diferentes níveis de vigor.

Este trabalho teve por objetivo avaliar os efeitos do condicionamento osmótico na germinação das sementes e no crescimento de plântulas de aspargo provenientes de diferentes lotes.

\section{MATERIAL E MÉTODOS}

O trabalho foi desenvolvido no Laboratório de Pesquisa de Sementes do Departamento de Fitotecnia da Universidade Federal de Viçosa, no período de janeiro a novembro/2000. Foram utilizados quatro lotes comerciais de sementes de aspargo (Asparagus officinalis L.), variedade 'Mary Washington', fornecidas pela Topseed Sementes (Agristar) que foram submetidos a diferentes tratamentos de condicionamento osmótico.

O condicionamento osmótico foi realizado em caixas plásticas (tipo gerbox), onde quatro gramas de sementes foram distribuídas sobre duas folhas de papel toalha umedecidas com $20 \mathrm{~mL}$ de solução de polietileno glicol (PEG 6000) com potencial de $-1,0$ e $-1,2 \mathrm{MPa}$. As concentrações foram obtidas segundo Villela et al. (1991). As caixas foram mantidas em estufa incubadora tipo BOD a $25^{\circ} \mathrm{C}$, por sete e 14 dias. As sementes foram, também, condicionadas em água do mar (potencial osmótico de $3,3 \mathrm{MPa}$ ) por sete e 14 dias e, em água destilada, por três 
dias, seguindo-se o mesmo procedimento descrito para o condicionamento em PEG. Os períodos de condicionamento adotados foram definidos de acordo com as curvas de embebição obtidas para cada lote e apresentadas por Bittencourt (2002). Todos os tratamentos foram acrescidos de $0,15 \%$ do ingrediente ativo do fungicida Captan 750 TS. Sementes não condicionadas foram utilizadas como testemunha.

Após o condicionamento, as sementes de cada tratamento foram lavadas em água corrente, secadas superficialmente e submetidas aos seguintes testes e determinações:

Grau de umidade: determinado em estufa a $105 \pm 3^{0} \mathrm{C}$ por 24 horas, segundo as recomendações das Regras para Análise de Sementes (Brasil, 1992), sendo os resultados expressos em porcentagem (base úmida).

Germinação: utilizaram-se quatro subamostras de 50 sementes distribuídas sobre três folhas de papel toalha, umedecidas com volume de água destilada equivalente a três vezes o peso do papel seco e dispostas em caixas plásticas (tipo gerbox), mantidas em germinador a $25^{\circ} \mathrm{C}$. A avaliação da porcentagem de plântulas normais foi realizada aos 13 e 28 dias após a semeadura (Brasil, 1992).

Velocidade de emergência de plântulas: quatro subamostras de 25 sementes foram semeadas eqüidistantemente em bandejas contendo areia umedecida com quantidade de água equivalente a $60 \%$ de sua capacidade de retenção. As bandejas foram mantidas em uma câmara de crescimento a $22^{\circ} \mathrm{C}$. Foram realizadas avaliações diárias até o $23^{\underline{0}}$ dia após a semeadura, ocasião em que ocorreu estabilização da emergência. A velocidade de emergência das plântulas, em dias, foi calculada segundo estabelecido por Edmond \& Drapala (1958) e descrito por Nakagawa (1999).

Comprimento da radícula: foram utilizadas quatro subamostras de dez sementes, que foram semeadas a $1,0 \mathrm{~cm}$ uma da outra, com o hilo apontado na mesma direção, sobre uma linha reta de 9,0 cm traçada ao longo da extremidade superior do papel toalha, colocado na base de caixas plásticas (tipo gerbox), usando-se a tampa encaixada sobre a base da caixa para fixar as sementes. Foram utilizadas três folhas de papel toalha umedecidas com volume de água destilada equivalente a três vezes o peso do papel seco. As caixas plásticas foram colocadas em germinador a $25^{\circ} \mathrm{C}$, distribuídas inclinadamente nas bandejas formando um ângulo de $45^{\circ}$, para facilitar o crescimento descendente das raízes e ascendente do epicótilo das plântulas. A avaliação foi realizada aos 12 dias após a semeadura, tomando-se o comprimento, em centímetros, das radículas das plântulas normais. O comprimento médio foi obtido somando-se as medidas tomadas para cada plântula e dividindo-se pelo número total de sementes por subamostra (25).

Comprimento das plântulas: foi realizado juntamente ao teste de comprimento da radícula, tomandose o comprimento, em centímetros, das plântulas normais.
Comprimento do epicótilo: foi realizado juntamente com o teste de comprimento da radícula, tomando-se o comprimento, em centímetros, do epicótilo das plântulas normais.

$\mathrm{O}$ delineamento experimental adotado foi $\mathrm{o}$ inteiramente casualizado com quatro repetições e oito tratamentos. Os dados foram submetidos aos testes de normalidade e homogeneidade de variância, que indicaram a não necessidade de transformação. Foram realizadas análises individuais de variância para cada lote. A seguir, foram processadas análises combinadas de variância sempre que a razão entre o maior e o menor QM residual das análises individuais fosse inferior a sete (Gomes, 1990). Os tratamentos e lotes foram comparados, respectivamente, pelos testes de Dunnett e Duncan, a 5\% de probabilidade.

\section{RESULTADOS E DISCUSSÃO}

$\mathrm{Na}$ Tabela 1, pode-se verificar que, para o lote 1 , a porcentagem de germinação das sementes condicionadas em PEG -1,0 MPa e PEG -1,2 MPa por 14 dias e em água do mar por sete dias foi significativamente superior à testemunha. Nota-se que estes tratamentos elevaram a germinação de $40 \%$, na semente não condicionada, para cerca de $60 \%$, que é o padrão mínimo de germinação estabelecido para a comercialização de sementes fiscalizadas de aspargo no Brasil (Brasil, 1986). Para os lotes 2 e 3, de alta germinação, o condicionamento osmótico das sementes não promoveu melhoria na germinação. No lote 4, os tratamentos PEG -1,0 MPa por sete dias e PEG -1,2 MPa por sete e 14 dias foram superiores à semente não condicionada.

TABELA 1. Médias da porcentagem de germinação de sementes de aspargo 'Mary Washington' oriundas de quatro lotes e submetidas a diferentes tratamentos de condicionamento osmótico.

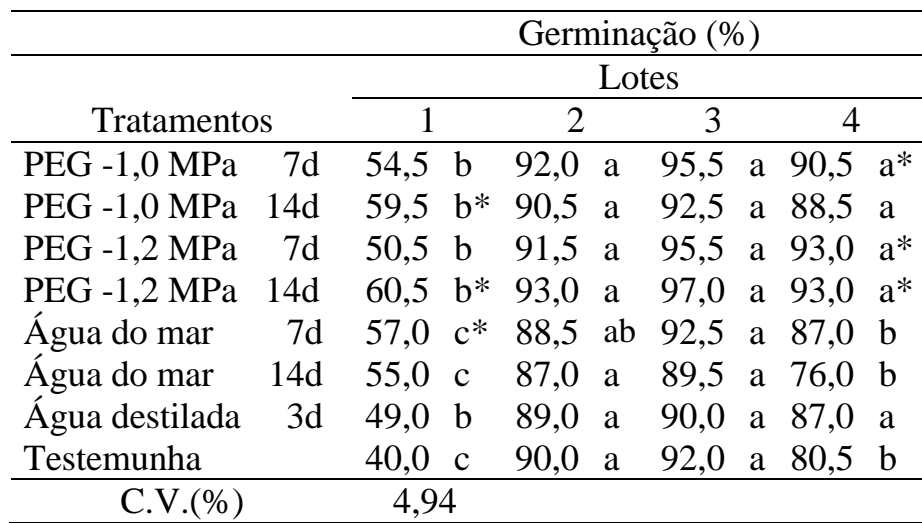

$\mathrm{Na}$ linha, médias seguidas pela mesma letra não diferem pelo teste Duncan, a $5 \%$.

$\mathrm{Na}$ coluna, médias seguidas de $*$ diferem significativamente da testemunha pelo teste de Dunnett, a 5\%. 
O uso de sementes de alto vigor é sugerido por Parera \& Cantliffe (1994) como pré-requisito para se obter um bom resultado com o condicionamento osmótico. Em contrapartida, Evans \& Pill (1989) não encontraram efeito benéfico do condicionamento sobre a germinação de um lote de aspargo com alta viabilidade (94\%). Entretanto, o condicionamento osmótico tem revigorado lotes de sementes de cenoura de baixa qualidade fisiológica (Szafirowska et al., 1981). Nota-se, no presente trabalho, que para o lote de menor qualidade fisiológica (lote 1), o aumento na germinação das sementes foi de $20 \%$ (Tabela 1) em comparação com a testemunha.

Pelos resultados da primeira contagem de germinação (Tabela 2), verifica-se que, para as sementes do lote 1 , houve superioridade dos tratamentos PEG -1,0 MPa e -1,2 MPa por 14 dias em relação à testemunha. Já para os lotes 2 e 3, o condicionamento osmótico não promoveu melhoria no desempenho das sementes. Por outro lado, para o lote 4, considerado de média qualidade fisiológica, o tratamento com PEG -1,2 MPa por 14 dias mostrou-se benéfico. Segundo Nakagawa (1999), sementes que apresentam maior porcentagem de plântulas normais na primeira contagem do teste de germinação são mais vigorosas por apresentarem maior velocidade de germinação. Verifica-se, portanto, que o condicionamento osmótico foi mais efetivo para as sementes de média e baixa qualidade (lotes 1 e 4 , respectivamente). É importante ressaltar que, no lote 1, as sementes não condicionadas apresentaram 19\% de plântulas normais aos 13 dias de germinação e esse valor aumentou para $50 \%$ após o condicionamento em PEG a -1,0 MPa por 14 dias, o que representa um ganho de $163,16 \%$. Nota-se, para esse lote, que os tratamentos PEG 1,0 e $-1,2 \mathrm{MPa}$ por 14 dias contribuíram para aumentar não só a velocidade de germinação (Tabela 2), princípio básico desse teste, como também a porcentagem de germinação (Tabela 1).

Comparando-se os resultados de germinação (Tabela 1) com os de primeira contagem (Tabela 2), verifica-se que, de modo geral, houve superioridade para os tratamentos PEG -1,0 MPa e PEG -1,2 MPa, por 14 dias. Frett et al. (1991) não obtiveram aumento significativo na porcentagem final de germinação das sementes de aspargo condicionadas por sete dias em PEG $6000 \mathrm{a}$ $0,8 \mathrm{MPa}$ ou em água do mar sintética, o que também já havia sido observado por Evans \& Pill (1989).

Pelos resultados de velocidade de $5 \%$. $5 \%$. emergência das plântulas (Tabela 3), verifica-se que, para todos os lotes, os tratamentos com PEG 6000, independentemente da concentração osmótica e do período, e a embebição em água destilada por três dias foram superiores em relação à testemunha. Apenas para o lote 1 , o condicionamento em água do mar por 14 dias aumentou a velocidade de emergência das plântulas em relação à testemunha. Para os demais lotes, o condicionamento em

TABELA 2. Médias da porcentagem de plântulas normais na primeira contagem do teste de germinação das sementes de aspargo 'Mary Washington' oriundas de quatro lotes e submetidas a diferentes tratamentos de condicionamento osmótico.

\begin{tabular}{|c|c|c|c|c|c|c|c|c|}
\hline & & \multicolumn{7}{|c|}{ Germinação na primeira contagem (\%) } \\
\hline \multirow{2}{*}{\multicolumn{2}{|c|}{ Tratamentos }} & \multicolumn{7}{|c|}{ Lotes } \\
\hline & & 1 & 2 & & 3 & & 4 & \\
\hline PEG -1,0 MPa & $7 \mathrm{~d}$ & $40,0 \mathrm{~b}$ & 91,0 & $\mathrm{a}$ & 95,0 & $\mathrm{a}$ & 88,5 & $\mathrm{a}$ \\
\hline PEG -1,0 MPa & $14 d$ & $50,0 \mathrm{~b}^{*}$ & 85,5 & $\mathrm{a}$ & 89,0 & $\mathrm{a}$ & 85,0 & $\mathrm{a}$ \\
\hline PEG -1,2 MPa & $7 d$ & $40,0 \mathrm{c}$ & 91,0 & $\mathrm{a}$ & 94,5 & $\mathrm{a}$ & 84,5 & b \\
\hline PEG -1,2 MPa & $14 d$ & $47,5 b^{*}$ & 90,0 & $\mathrm{a}$ & 96,5 & $\mathrm{a}$ & 92,0 & $a^{*}$ \\
\hline Água do mar & $7 d$ & $40,0 \mathrm{c}$ & 87,0 & $\mathrm{~b}$ & 91,5 & $\mathrm{a}$ & 83,5 & $\mathrm{~b}$ \\
\hline Água do mar & $14 d$ & $40,0 \quad \mathrm{c}$ & 81,5 & $\mathrm{a}$ & 87,5 & $\mathrm{a}$ & 68,0 & b \\
\hline Água destilada & $3 d$ & $28,0 \quad c$ & 87,0 & $a b$ & 89,5 & $\mathrm{a}$ & 84,5 & b \\
\hline Testemunha & & $19,0 \mathrm{c}$ & 84,0 & $\mathrm{a}$ & 90,5 & $a$ & 65,5 & $\mathrm{~b}$ \\
\hline
\end{tabular}

C.V. (\%)

5,77

Na linha, médias seguidas pela mesma letra não diferem pelo teste Duncan, a

Na coluna, médias seguidas de * diferem significativamente da testemunha pelo teste de Dunnett, a $5 \%$.

TABELA 3. Médias da velocidade de emergência (dias) em areia de plântulas de aspargo 'Mary Washington' oriundas de sementes de quatro lotes e submetidas a diferentes tratamentos de condicionamento osmótico.

\begin{tabular}{|c|c|c|c|c|c|}
\hline \multirow[b]{3}{*}{ Tratamentos } & \multicolumn{5}{|c|}{ Velocidade de emergência (dias) } \\
\hline & \multicolumn{5}{|c|}{ Lotes } \\
\hline & 1 & 2 & & 3 & 4 \\
\hline PEG -1,0 MPa & $15,78 \mathrm{a}^{*}$ & 11,85 & $b^{*}$ & $10,38 \mathrm{c}^{*}$ & $11,81 \mathrm{~b}^{*}$ \\
\hline PEG -1,0 MPa 14d & $13,61 \mathrm{a}^{*}$ & 10,66 & $b^{*}$ & $9,36 \mathrm{~b}^{*}$ & $9,99 \mathrm{~b}^{*}$ \\
\hline PEG -1,2 MPa & $15,46 \mathrm{a}^{*}$ & 11,49 & $\mathrm{bc}^{*}$ & $10,67 \mathrm{c}^{*}$ & $11,84 b^{*}$ \\
\hline PEG -1,2 MPa 14d & $14,59 \mathrm{a}^{*}$ & 11,57 & $b^{*}$ & $10,50 b^{*}$ & $10,87 b^{*}$ \\
\hline Água do mar & $16,95 \mathrm{a}$ & 13,04 & b & $12,61 \mathrm{~b}$ & $13,12 \mathrm{~b}$ \\
\hline Água do mar & $15,80 \mathrm{a}^{*}$ & 13,01 & $\mathrm{c}$ & $12,50 \mathrm{c}$ & $14,04 \quad b$ \\
\hline Água destilada 3d & $16,06 \mathrm{a}^{*}$ & 10,80 & $b^{*}$ & $10,81 b^{*}$ & $11,46 \mathrm{~b}^{*}$ \\
\hline Testemunha & $18,24 \mathrm{a}$ & 14,06 & $\mathrm{~b}$ & $14,01 \mathrm{~b}$ & $14,71 \quad b$ \\
\hline C.V. (\%) & 6,04 & & & & \\
\hline
\end{tabular}

$\mathrm{Na}$ linha, médias seguidas pela mesma letra não diferem pelo teste Duncan, a

$\mathrm{Na}$ coluna, médias seguidas de $*$ diferem significativamente da testemunha pelo teste de Dunnett, a 5\%. 
água do mar por sete e 14 dias não se mostrou benéfico. Já para o lote 2, apenas os tratamentos de condicionamento em água do mar não diferiram significativamente da semente não condicionada. Assim, o condicionamento osmótico se mostrou eficiente para acelerar a germinação das sementes de aspargo não afetando, contudo, a porcentagem final de germinação.

Quanto ao comprimento da radícula, também houve favorecimento pelo uso de PEG por 14 dias para as sementes do lote 1 (Tabela 4). Verificou-se ainda, que mesmo para o lote 2, considerado de alta qualidade fisiológica, o condicionamento osmótico promoveu a obtenção de radículas com comprimento superior ao dobro do que foi obtido em sementes não condicionadas, quando se utilizou PEG 6000, em ambos os potenciais osmóticos e períodos de tempo testados. Resultados semelhantes foram constatados para sementes do lote 4, de alta qualidade fisiológica. Já os tratamentos com água destilada e água do mar, para os quatro lotes, não promoveram aumentos significativos nos comprimentos de radícula em relação à testemunha. Trigo et al. (1999) também obtiveram incrementos no comprimento da raiz primária em cebola com o osmocondicionamento das sementes. Resultados semelhantes também foram verificados em plântulas de mostarda por Srinivasan et al. (1999). Durante o condicionamento osmótico ocorrem incrementos no teor de proteínas solúveis e de enzimas específicas, o que proporciona maior concentração de solutos, resultando em crescimento mais rápido e, por conseqüência, maior acúmulo de biomassa (Smith \& Cobb, 1991). A melhoria no desempenho das sementes após o condicionamento osmótico tem sido correlacionada com processos de reparo macromolecular que ocorrem durante o tratamento (Lanteri et al., 1998). Por outro lado, diversos autores relatam que o principal efeito do condicionamento osmótico é aumentar a velocidade de emergência das plântulas, o que influenciará no tamanho e desenvolvimento das plântulas (Khan et al., 1978; Bradford, 1986; Khan, 1992). Em sementes de melancia, Demir \& Van de Venter (1999) demonstraram que o condicionamento osmótico resultou em emergência mais rápida e aumento na porcentagem de emergência indicando, ainda, que o efeito benéfico do tratamento se estendeu além da emergência da radícula, refletindo no vigor das plântulas.

Pela Tabela 5, verifica-se, para o lote 1, que plântulas de maior tamanho, em relação à testemunha, foram obtidas de sementes submetidas ao condicionamento em PEG -1,0 e -1,2 MPa, por 14 dias. Para os lotes 2 e 4, todos os tratamentos com PEG foram benéficos quando comparados à testemunha não condicionada, o que também foi verificado ao se avaliar o comprimento do epicótilo (Tabela 6). Já o condicionamento em água do mar e em água destilada não foram efetivos quando comparados à testemunha. Apenas para o lote 3 , o condicionamento em água destilada por três dias promoveu aumento no comprimento da plântula e do epicótilo em relação à testemunha. Para as sementes deste lote, o condicionamento com PEG -1,0 MPa por sete dias mostrou-se benéfico ao crescimento da plântula. Com relação ao comprimento do epicótilo das plântulas do lote 3 (Tabela 6), todos os tratamentos com PEG 6000 foram significativamente superiores à testemunha. Verifica-se,

TABELA 4. Médias do comprimento da radícula (cm/plântula) em plântulas de aspargo 'Mary Washington' oriundas de sementes de quatro lotes e submetidas a diferentes tratamentos de condicionamento osmótico.

\begin{tabular}{|c|c|c|c|c|c|c|}
\hline & \multicolumn{6}{|c|}{ Comprimento da radícula $(\mathrm{cm} /$ plântula $)$} \\
\hline \multirow[b]{2}{*}{ Tratamentos } & \multicolumn{6}{|c|}{ Lotes } \\
\hline & 1 & 2 & & 3 & & 4 \\
\hline $\begin{array}{l}\text { PEG -1,0 MPa } 7 \mathrm{~d} \\
\end{array}$ & $1,61 \mathrm{~b}$ & 5,54 & $a^{*}$ & 5,69 & $\mathrm{a}$ & $4,55 \mathrm{a}^{*}$ \\
\hline PEG - $1,0 \mathrm{MPa} 14 \mathrm{~d}$ & $2,25 \mathrm{c}^{*}$ & 6,11 & $a^{*}$ & 4,86 & $\mathrm{~b}$ & $4,76 \mathrm{~b}^{*}$ \\
\hline PEG -1,2 MPa & $1,24 \mathrm{~b}$ & 4,43 & $a^{*}$ & 4,60 & $\mathrm{a}$ & $4,90 \mathrm{a}^{*}$ \\
\hline PEG -1,2 MPa 14d & $2,15 \mathrm{~b}^{*}$ & 5,02 & $a^{*}$ & 5,28 & $\mathrm{a}$ & $5,07 \mathrm{a}^{*}$ \\
\hline Água do mar & $1,01 \mathrm{~b}$ & 4,14 & $\mathrm{a}$ & 3,99 & $\mathrm{a}$ & 3,80 a \\
\hline Água do mar & $1,66 \mathrm{~b}$ & 3,98 & $\mathrm{a}$ & 3,70 & $\mathrm{a}$ & $2,75 \mathrm{ab}$ \\
\hline Água destilada & $0,82 \mathrm{c}$ & 3,75 & $\mathrm{~b}$ & 5,74 & $\mathrm{a}$ & $3,60 \mathrm{~b}$ \\
\hline Testemunha & $0,48 \quad \mathrm{c}$ & 2,52 & $\mathrm{~b}$ & 3,64 & $\mathrm{a}$ & $2,24 \mathrm{~b}$ \\
\hline C.V. (\%) & 17,89 & & & & & \\
\hline
\end{tabular}

Na linha, médias seguidas pela mesma letra não diferem pelo teste Duncan, a $5 \%$.

$\mathrm{Na}$ coluna, médias seguidas de $*$ diferem significativamente da testemunha pelo teste de Dunnett, a 5\%.

TABELA 5. Médias do comprimento da plântula (cm/plântula) de aspargo 'Mary Washington' oriundas de sementes de quatro lotes e submetidas a diferentes tratamentos de condicionamento osmótico.

\begin{tabular}{|c|c|c|c|c|c|c|}
\hline & \multicolumn{6}{|c|}{ Comprimento da plântula (cm/plântula) } \\
\hline \multirow[b]{2}{*}{ Tratamentos } & \multicolumn{6}{|c|}{ Lotes } \\
\hline & 1 & \multicolumn{2}{|c|}{2} & \multicolumn{2}{|c|}{3} & 4 \\
\hline PEG - 1,0 MPa & $2,46 \mathrm{~b}$ & 8,13 & $a^{*}$ & 8,48 & $\mathrm{a}^{*}$ & $7,08 \mathrm{a}^{*}$ \\
\hline PEG - 1,0 MPa 14d & $3,35 \mathrm{c}^{*}$ & 9,28 & $a^{*}$ & 7,71 & $\mathrm{~b}$ & $7,02 b^{*}$ \\
\hline PEG -1,2 MPa & $1,79 \mathrm{~b}$ & 6,62 & $a^{*}$ & 6,59 & $\mathrm{a}$ & $7,04 \mathrm{a}^{*}$ \\
\hline PEG - 1,2 MPa 14d & $3,34 b^{*}$ & 7,57 & $a^{*}$ & 7,83 & a & $7,90 \mathrm{a}^{*}$ \\
\hline Água do mar & $1,29 \mathrm{~b}$ & 5,73 & $\mathrm{a}$ & 5,86 & $\mathrm{a}$ & 5,32 a \\
\hline Água do mar & $2,34 \mathrm{~b}$ & 5,44 & a & 5,49 & a & $3,56 \mathrm{~b}$ \\
\hline Água destilada & $1,37 \mathrm{c}$ & 5,69 & $b$ & 8,26 & $\mathrm{a} *$ & $5,40 \mathrm{~b}$ \\
\hline Testemunha & $0,54 \mathrm{c}$ & 3,62 & $\mathrm{~b}$ & 5,19 & $\mathrm{a}$ & $3,23 \mathrm{~b}$ \\
\hline C.V. $(\%)$ & 16,70 & & & & & \\
\hline
\end{tabular}

$\mathrm{Na}$ linha, médias seguidas pela mesma letra não diferem pelo teste Duncan, a $5 \%$.

$\mathrm{Na}$ coluna, médias seguidas de $*$ diferem significativamente da testemunha pelo teste de Dunnett, a 5\%. 
TABELA 6. Médias do comprimento do epicótilo (cm/plântula) em plântulas de aspargo 'Mary Washington' oriundas de sementes de quatro lotes e submetidas a diferentes tratamentos de condicionamento osmótico.

\begin{tabular}{|c|c|c|c|c|c|c|c|c|}
\hline & & \multicolumn{7}{|c|}{ Comprimento do epicótilo ( $\mathrm{cm} /$ plântula) } \\
\hline \multirow{2}{*}{\multicolumn{2}{|c|}{ Tratamentos }} & \multicolumn{7}{|c|}{ Lotes } \\
\hline & & 1 & & 2 & & 3 & & 4 \\
\hline PEG -1,0 MPa & $7 d$ & 0,85 & $\mathrm{~b}$ & 2,60 & $a^{*}$ & 2,79 & $\mathrm{a}^{*}$ & $2,53 \mathrm{a}^{*}$ \\
\hline PEG -1,0 MPa & $14 \mathrm{~d}$ & 1,10 & $c^{*}$ & 3,17 & $a^{*}$ & 2,86 & $a^{*}$ & $2,26 \mathrm{~b}^{*}$ \\
\hline PEG -1,2 MPa & $7 d$ & 0,54 & $\mathrm{~b}$ & 2,19 & $a^{*}$ & 1,99 & $a^{*}$ & $2,14 \mathrm{a}^{*}$ \\
\hline PEG -1,2 MPa & $14 \mathrm{~d}$ & 1,19 & $b^{*}$ & 2,55 & $a^{*}$ & 2,55 & $a^{*}$ & $2,83 \mathrm{a}^{*}$ \\
\hline Água do mar & $7 d$ & 0,29 & $\mathrm{~b}$ & 1,59 & $\mathrm{a}$ & 1,87 & $\mathrm{a}$ & $1,52 \mathrm{a}$ \\
\hline Água do mar & $14 d$ & 0,69 & $\mathrm{~b}$ & 1,46 & $\mathrm{a}$ & 1,79 & $\mathrm{a}$ & $0,82 \mathrm{~b}$ \\
\hline Água destilada & $3 d$ & 0,55 & $\mathrm{c}$ & 1,95 & $\mathrm{~b}$ & 2,52 & $a^{*}$ & $1,80 \mathrm{~b}$ \\
\hline Testemunha & & 0,06 & $\mathrm{c}$ & 1,11 & $\mathrm{~b}$ & 1,56 & $\mathrm{a}$ & $1,00 \mathrm{~b}$ \\
\hline C.V. (\%) & & 19,71 & & & & & & \\
\hline
\end{tabular}

Na linha, médias seguidas pela mesma letra não diferem pelo teste Duncan, a $5 \%$.

$\mathrm{Na}$ coluna, médias seguidas de * diferem significativamente da testemunha pelo teste de Dunnett, a 5\%.

portanto, de modo geral, que as plântulas que emergiram mais rápido (Tabela 3) também apresentaram maior tamanho (Tabela 5) e maior comprimento de radícula e de epicótilo (Tabelas 4 e 6 , respectivamente), sugerindo que a velocidade de emergência influenciou o desenvolvimento das plântulas.

Uma análise geral dos resultados permite afirmar que as sementes do lote 1, para todos os tratamentos $\mathrm{e}$ características avaliadas, apresentaram-se inferiores às dos lotes 2, 3 e 4. De modo geral, os lotes 2 e 3 apresentaram qualidade fisiológica semelhante, com desempenho superior às do lote 4 (Tabelas 1 a 6). Verificou-se ainda, considerando-se todas as características avaliadas, que efeitos mais expressivos do condicionamento osmótico foram verificados para as sementes de menor qualidade fisiológica, especialmente do lote 1. É possível constatar também, que os tratamentos com PEG por sete e 14 dias tenderam a ser superiores aos tratamentos com água do mar. Evans \& Pill (1989), Frett et al. (1991) e Pill et al. (1991) obtiveram melhores resultados com o condicionamento de sementes de aspargo em PEG durante sete dias. Deve-se considerar, contudo, que diferentemente do presente trabalho, em que se avaliou o efeito do condicionamento em sementes de aspargo oriundas de quatro lotes com qualidades distintas, todos os autores citados avaliaram apenas um lote de sementes.

Embora não haja ainda informações consistentes sobre o uso de água do mar natural como agente condicionador, a potenciais osmóticos bem mais baixos que os usados comumente em soluções de PEG, deve-se considerar, com base nos resultados obtidos neste trabalho, que para todos os testes realizados, não houve efeito prejudicial à germinação pelo uso da água do mar, quando se compara às sementes não condicionadas, provavelmente devido à maior tolerância dessa espécie em soluções salinas sugerida por François (1987). Frett et al. (1991) constataram que a água do mar sintética foi tão efetiva quanto o PEG 8000 no condicionamento de sementes de aspargo, enquanto que em sementes de tomate, o uso de água do mar ou de soluções salinas se mostrou mais eficiente que o PEG para acelerar a germinação.

\section{CONCLUSÕES}

O condicionamento em PEG 6000 foi o tratamento mais adequado para promover melhoria no desempenho das sementes de aspargo.

O condicionamento osmótico permitiu aumentar a germinação apenas das sementes de menor qualidade fisiológica.

Efeitos benéficos do condicionamento osmótico foram mais expressivos na velocidade de emergência e no crescimento das plântulas, independentemente do nível de qualidade fisiológica das sementes.

\section{REFERÊNCIAS}

BITTENCOURT, M.L.C. Condicionamento osmótico de sementes de aspargo (Asparagus officinalis L.). Viçosa. 2002. 95f. Tese (Doutorado em Fitotecnia)- Universidade Federal de Viçosa, Viçosa, 2002.

BRADFORD, K.J. Manipulation of seed water relations via osmotic priming to improve germination under stress conditions. HortScience, Alexandria, v.21, n.5, p.11051112,1986

BRASIL. Portaria n ${ }^{\circ}$ 457/1986, de 18 de dezembro de 1986. Ministério da Agricultura. Diário Oficial da União, Brasília, dezembro de 1986. Seção 1, p. 19653.

BRASIL. Ministério da Agricultura e da Reforma Agrária. Regras para análise de sementes. Brasília: SNDA/DNDV/CLAV, 1992. 365p.

DEMIR, I. ; VAN DE VENTER, H.A. The effect of priming treatments on the performance of watermelon (Citrullus lanatus (Thunb.) Matsum. \& Nakai) seeds under temperature and osmotic stress. Seed Science and Technology, Zürich, v.27, n.3, p.871-875, 1999.

EDMOND, J.B.; DRAPALA, W.J. The effects of temperature, sand, soil, and acetone on germination of okra seeds. Proc. Am. Soc. Hort. Sci., Itahaca, v.71, p.428-434, 1958.

EVANS, T.A.; PILL, W.G. Emergence and seedling growth from osmotically primed or pregerminated seeds of asparagus (Asparagus officinalis L.). The Journal of Horticultural Science, London, v.64, n.3, p.275-282, 1989. 
FRANCOIS, L.E. Salinity effects on asparagus yield and vegetative growth. Journal of the American Society for Horticultural Science, Alexandria, v.112, n.3, p.432-436, 1987.

FRETT, J.J.; PILL， W.G. ; MORNEAU, D.C. A comparison of priming agents for tomato and asparagus seeds. HortScience, Alexandria, v.26, n.9, p.1158-1159, 1991.

GOMES, F.P. Curso de estatística experimental. Piracicaba: ESALQ/USP, 1990. 460p.

HAIGH, A.M.; BARLOW, E.W.R. Germination and priming of tomato, carrot, onion, and sorghum seeds in a range of osmotica. Journal of the American Society for Horticultural Science, Alexandria, v.112, n.2, p.202-208, 1987.

JETT, L.W.; WELBAUM, G.E. Changes in broccoli (Brassica oleracea L.) seed weigh, viability, and vigor during development and following drying and priming. Seed Science and Technology, Zürich, v.24, n.1, p.127137, 1996

KHAN, A.A. Preplant physiological seed conditioning. Horticultural Reviews, New York, v.13, n.1, p.131-181, 1992.

KHAN, A.A.; TAO, K.L.; KNYPL, J.S.; BORKOWSKA, B.; POWELL, L.E. Osmotic conditioning of seeds: physiological and biochemical changes. Acta Horticulturae, Wageningen, v.83, p.267-283, 1978.

KHARUP, A. Asparagus seed priming with magnesium sulphate and polyethylene glycol. Asparagus Research Newsletter, Palmerston, v.6, n.1, p.17, 1988.

LANTERI, S.; QUAGLIOTTI, L.; BELLETTI, P. Delayed luminescence and priming-induced nuclear replication of unaged and controlled deteriorated pepper seeds (Capsicum аппиит L.). Seed Science and Technology, Zürich, v.26, n.2, p.413-424, 1998 .

NAKAGAWA, J. Testes de vigor baseados no desempenho das plântulas. In: KRZYZANOWSKI, F.C.; VIEIRA, R.D. ; FRANÇA NETO, J.B. (Ed.). Vigor de sementes: conceitos e testes. Londrina: ABRATES, 1999. p.1-24.

NASCIMENTO, W.M. Condicionamento osmótico de sementes de hortaliças: potencialidades e implicações. Horticultura Brasileira, Brasília, v.16, n.2, p.106-109, 1998.

ODELL, G.B.; CANTLIFFE, D.J. Seed priming procedures and the effect of subsequent storage on the germination of fresh market tomato seeds. Proceedings of the Florida State Horticultural Society, Lake Alfred, v.99, p.303-306, 1986.
PARERA, C.A.; CANTLIFFE, D.J. Presowing seed priming. Horticultural Reviews, New York, v. 16, n.1, p. 109-141, 1994.

PILL, W.G. Parsley emergence and seedling growth from raw, osmoconditioned and pregerminated seeds. HortScience, Alexandria, v.21, n.5, p.1134-1136, 1986.

PILL, W.G.; FINCH-SAVAGE, W.E. Effects of combining priming and plant growth regulator treatments on the synchronization of carrot seed germination. Annals of Applied Biology, Warwick, v.113, n.2, p.383-389, 1988.

PILL, W.G.; FRETT, J.J.; MORNEAU, D.C. Germination and seedling emergence of primed tomato and asparagus seeds under adverse conditions. HortScience, Alexandria, v.26, n.9, p.1160-1162, 1991.

SMITH, P.T.; COBB, B.G. Accelerated germination of pepper seed by priming with salt solutions and water. HortScience, Alexandria, v.26, n.4, p.417-419, 1991.

SRINIVASAN, K.; SAXENA, S.; SINGH, B.B. Osmo- and hydropriming of mustard seeds to improve vigour and some biochemical activities. Seed Science and Technology, Zürich, v. 27, n.2, p.785-793, 1999.

STOFFELLA, P.J.; DIPAOLA, M.L.; PARDOSSI, A.; TOGNONI, F. Seedling root morphology and shoot growth after seed priming of pregerminated bell pepper. HortScience, Alexandria, v.27, n.3, p.214-215, 1992.

SZAFIROWSKA, A.; KHAN, A.A.; PECK, N.H. Osmoconditioning of carrot seeds to improve seedling establishment and yield in cold soil. Agronomy Journal, Madison, v.73, n.5, p.845-848, 1981.

TIESSEN, H.; FITTS, M.; MAPPLEBECK, L. Influence of treating seed with nutrient solutions on the percent and rate of emergence of asparagus. Asparagus Research Newslleter, Palmerston, v.1, n.2, p.3, 1983.

TRIGO, M.F.O.O.; NEDEL, J.L.; LOPES, N.F.; TRIGO, L.F.N. Osmocondicionamento de sementes de cebola (Allium cepa L.) com soluções aeradas de polietileno glicol. Revista Brasileira de Sementes, Londrina, v.21, n.1, p.145-150, 1999.

VILLELA, F.A.; DONI FILHO, L.; SEQUEIRA, E.L. Tabela de potencial osmótico em função da concentração de polietileno glicol 6000 e da temperatura. Pesquisa Agropecuária Brasileira, Brasília, v.26, n.11/12, p.19571968, 1991.

WURR, D.C.R.; FELLOWS, J.R. The effects of grading and priming seeds of crisp cv. Saladin, on germination at high temperature, seed vigour, and crop uniformity. Annals of Applied Biology, Warwick, v.105, n.2, p.345-352, 1984. 